\title{
MEMORY AND THE DIASPORIC CREATIVE IMAGINATION: PREETA SAMARASAN'S EVENING IS THE WHOLE DAY
}

\author{
Shanthini Pillai \\ Universiti Kebangsaan Malaysia \\ spillai2900@gmail.com
}

\begin{abstract}
The focal point of this paper is the concept of transnational memory and the blurred and fluctuating boundaries of ties with the nation that was once home as depicted in Evening is the Whole Day, a novel by Preeta Samarasan, part of the emergent community of new Malaysian diasporic writers. New Malaysian diasporic writers in the context of this paper are taken to refer to writers who were born in Malaysia but are now settled elsewhere in the globe, and yet are recognizably transnational in that their writings focus on the older country and memories of family, community, and a nation that once was. The discussion expands existing scholarship on diasporic memory such as Rushdie's argument of the broken mirrored refractions by introducing the concept of another cartography of memory, that of appendages of Other memories such as fleeting images from the repertoire of literary (and historical) archives, textual tradition, and its influence on diasporic creative writing. This is framed against Arjun Appadurai's notion of the "synchronic warehouse," a term he has used to refer to the "politics of memory" that reside within the concept of "the past" that no longer reflects a simple return but a space which allows for the recasting, redirecting, and editing of memories. Seen in this light, the paper concludes that the novel becomes the synchronic warehouse that projects a multiple imagined perspective of the nation, reimagined in a multitude of scenes that ultimately appear distinctly anomalous.
\end{abstract}

Keywords

hybridity, imaginary homelands, motherland, transnational memory

\section{About the author}

Shanthini Pillai is Associate Professor and Head of Literatures in English Programme at the School of Language Studies and Linguistics, Faculty of Social Sciences and Humanities, Universiti Kebangsaan Malaysia. Her research interests include diaspora and transnationalism in literary and cultural texts, literature in the real world, and multimodality and higher education literature learning. She is author of Colonial Visions, Postcolonial Revisions: Images of the Indian Diaspora of Malaysia. She is a recipient of the 2006-2007 Australia-Malaysia Institute Fellowships and Director of Research and Development for the Malaysian English Language Teaching Association (MELTA).

\section{INTRODUCTION}

For a very long time, when diaspora was the focus of Malaysian writings in English, the tendency was to highlight the experience of the classic diaspora - the migrant Chinese and Indian communities who left their ancestral homeland to settle in Malaya. Over time, however, there 
grew another strand in the Malaysian diasporic experience, colored by the experience of migration to the Metropolitan. This article focuses on the latter experience, which can be can be envisioned in two generational communities, the first being the classical or pioneering group of writers who felt compelled to leave the country in the wake of the riots of 1969, the second consisting of either descendants of the families that left Malaysia during the infamous riots or those who left the country to pursue their studies and subsequently stayed abroad.

Much has been written about the first group of writers, the notable figures that include Shirley Lim, Hilary Tham, Ee Tiang Hong, and Beth Yahp. The leave taking of many of these writers can in all probability be contextualized within the following scenario that Mishra speaks of:

Whenever the nation-state is perceived as racist or imperialist ... and the therapy of self-representation is denied to diasporic people, a state of melancholy sets in since the primal loss (of the homeland) cannot be replaced by the "new object of love." (36)

The pages of creative fiction produced by writers of the Malaysian diaspora seem to permeate with such melancholy, for as each writer partakes in some form of therapy of selfrepresentation of both self and (former) country, alongside are intimations of both the sting of negation from, and the poignancy of, a remembered home. As Shirley Lim has expressed, "after the disillusionment of the May 13 [1969] riots ... I had no nationalist idealism to imagine. The cultural parochialism that took shape in the aftermath of the riots in Malaysia, which includes race-based quotas, communalist politics, and separatist race-essentialized cultures, was absolute anathema to me" (279). The same sentiment can be perceived in the regular refrains of rejection in the poems of Ee Tiang Hong, such as "Tranquerah Road": "I had no choice but to go/to leave all I loved" (65), or "Heeren Street": "Departures are those consequences you set out ... the consequences of a decision/ taken elsewhere/to which we were no party" (57). These wounds of the past appear to reside deep in the recesses of the creative imagination, and time and again we find allusions to this dark period in the Malaysian history. As Subramaniam and Pillai have argued, "a rhetoric of blame appears to permeate the consciousness of many writers of the Malaysian Chinese diaspora whose cultural memory of the older country lies entombed with the ghost of the 1969 racial riots and the forcible departure that ensued" (56). Yet intertwined with this deep sense of betrayal is also a strong sense of place, as the creative text becomes the platform for the transnational negotiation of memory and space for the displaced Malaysian self. Take for instance the following assertion by Shirley Lim in a recent interview:

Much of my imagination has been and continues to be located in my earlier experiences as a Malaysian. After all, not only was I 24 years old when I left Kuala 
Lumpur for Boston but I return home frequently to visit my numerous brothers, relatives, and friends. The prospect of spending a good part of my later years in Malaysia is very much a possibility. (Quayum and Lim 294)

Witness that the notion of the " $\mathrm{I}$ " in the passage is interspersed with intimations of the transnational Malaysian, in the frequent visits home. Many of Ee Tiang Hong's poems also carry a strong sense of affinity with the physical landscape, mainly the town of Malacca, as much as they emanate with the sharp tones of betrayal (Subramaniam and Pillai). These etchings of the lost homeland that reside at the core of the writings are accessed through both remembered spaces and interactive visits. The potency of such memories is far reaching, and we can find them even in the cradle of writings of the new diasporic writers, the second generational community alluded to earlier. Amongst this second generation of Malaysian diasporic writers are, to name but a few from what appears to be a burgeoning group, Preeta Samarasan along with Tash Aw, Hsu Ming Teo, and Tan Twan Eng. This paper emerges from a larger research project that focuses on the four writers here named and presents the first quarter of the research based on a reading of Preeta Samarasan's Evening is the Whole Day.

\section{MEMORY AND THE DIASPORIC CREATIVE IMAGINATION OF PREETA SAMARASAN}

Preeta Samarasan left Malaysia for the United States when she was a teenager and subsequently settled in France where she currently resides. In an interview published on the Random House website featuring winners of the O. Henry Prize-winning authors, Samarasan has this to say of her writing:

I've read a lot and thought a lot about writing; I've studied with some great teachers, discussed craft and style and inspiration in workshop after workshop, but when it comes down to it, I cannot write without both that sadness and that anger. I read the news, talk to friends and relatives in Malaysia, and go home every year just to feel that all over again, just as sharply as when I lived there, if not more so.

Her words emphasize key aspects of transnational writings, that of memory and transatlantic journeys. It also calls attention to the influence of the tradition of writing on authors, and perhaps how these inform and influence the art of writing. This paper will reveal the ways in which there appears to be a syncretism of inherited memories of Malaysia and that of other memories from pages of canonical writings that might have influenced her creative writing. 
It argues that as the creative imagination tends to the sutures in the gauzy fabric of memory, memories of Other stories make their way into the forefront, and these are drawn from the pages of canonical literary tradition. This might be due to the fact that Samarasan left Malaysia in her teenage years and completed high school in the United States, perhaps retaining the repertoire of Western canonical literary writings that would have abounded in the syllabus of most American schools in the late eighties or early nineties. The ensuing discussion will focus on the syncretism of folk memory (stories inherited from the family), memories of physical landscapes, and canonical allusions (echoes of stories from writers of the Western canon) as revealed in the pages of Samarasan's novel, Evening is the Whole Day.

Evening is the Whole Day chronicles the lives of an upper-middle class diasporic Indian family in Malaysia, tracing its background from the early nineteenth century to the late eighties. The text is set in the northern town of Ipoh and recounts the difficulties, secrets, and prejudices within this family, events of which are intricately intertwined with the unfurling of the emerging nation state of Malaysia. These events come to the fore through memories of the various characters that occupy the narrative space, and as we follow the sequence of events, we encounter common signifiers of the diasporic experience.

\section{TRANSNATIONAL CARTOGRAPHIES OF MALAYSIA}

In the early nineties, Salman Rushdie spoke of the now infamous concept of the imaginary homeland and the fragmented vision of diasporic memory that is more often than not refracted through broken mirrors. As he writes, primarily of the diasporic Indian writer:

If we do look back we must also do so in the knowledge-which gives rise to profound uncertainties - that our physical alienation from India almost inevitably means that we will not be capable of reclaiming precisely the thing that was lost; that we will, in short, create fictions, not actual cities or villages, but invisible ones, imaginary homelands, Indias of the mind. (10)

Rushdie's concept ties in with the recreation of the diasporic experience inherent within transnational writing. The ethnic diasporic experience is often reconstructed in a space that is layered with multiple storylines refracted from these shards of memories. Because of the fragility of the collected memory of the homeland, transnational authors secure these memories through the act of reconstruction from the imagined and the real. However, the discussion adds another thread to existing thoughts on diasporic memory by introducing the concept of another cartography of 
memory, that of textual tradition and its influence on diasporic creative recollection. It argues that as the gaps and slippages arising from the broken mirrored refractions that Rushdie alludes to materialize in the act of putting together the creative product, appendages of Other memories such as fleeting images from the repertoire of literary (and historical) archives make their way into the mainframe, and fractured memory is recollected. Here, Arjun Appadurai's notion of the "synchronic warehouse" would be most applicable, a term he has used to refer to the "politics of memory" that reside within the concept of "the past" that no longer reflects a simple return but a space which allows for the recasting, redirecting, and editing of memories (29). Seen in this light, the novel becomes the synchronic warehouse that projects a multiple imagined perspective of the nation, reimagined in a multitude of scenes that ultimately appear distinctly anomalous.

Take the first few sentences of the novel, for example. At the very beginning of the narration, a bestial metaphor is used when the land of Malaysia is introduced to us:

There is, stretching delicate as a bird's head from the thin neck of the Kra Isthmus, a land that makes up half of the country called Malaysia. Where it dips its beak into the South China Sea, Singapore hovers like a bubble escaped from its throat. This bird's head is a springless summerless autumnless winterless land. (1)

The excerpt reveals two significant aspects, the first is the obvious bestial association that Malaysia is painted with, more importantly at the very opening sequence of the text. The immediate image that is conjured of the nation for the reader is both repulsive and grotesque. The country is perceived as a bird's head supported by a "thin neck," and with no accompanying visualization of an attached body, the head appears to be both dismembered and abnormal. The lack of a body and the emaciated support for the head suggest the incomplete wholeness of the country, making it appear in many instances fragile and unstable. It is this description of the nation that first greets the reader, and in many senses it portrays the scripting of a nation that is both cadaverous as much as it is envisioned to be delicate. The second significant aspect is the delineation of the country as "springless summerless autumnless winterless," thereby suggesting a lack of seasonal change and with it a hint of monotony. Here again it appears that the gaps in the recollections of the homeland are fused with images that echo the strategy of Othering weather conditions often witnessed in fiction on colonial Malaya. Seen against the subtext of another condition, the Malaysian environment with its tropical variations is consequently rendered as the Other through an emphasis of its absence of climactic change and variation. In this way, the transnational imaginary of Samarasan can be seen to echo Appadurai's notion of the disjunctures and irregularities that result from global movements, of "the deeply perspectival constructs, inflected by the historical, linguistic, 
and political situatedness of different sorts of actors; nation-states, multinationals, diasporic communities" where he adds that these "landscapes are eventually navigated by agents who both experience and constitute larger formations, in part by their own sense of what these landscapes offer" (31). The reconstitution of the Malaysian climate navigated by the transnational imaginary into a setting that reflects the absence of a familiar seasonal variety reflects the very disjuncture in its situated tropical distinctiveness.

This feature of an all consuming mélange is further evident in the picturing of time and, with it, memory: "Every day appears to begin with a blaze and end with this deluge, so that past and present and future run together in an infinite, steaming river" (1). The description here seems to mirror E.M Foster's famed account of India and the Marabar caves in A Passage to India where everything merges into one another, indiscernibly invariable. Memories of Malaysia thus seem to intersect with the canonical repertoire of the Oriental Other, reflecting another dimension of the transnational literary imaginary, that of the influence of canonical writings, as noted in the outset. Furthermore, in another interview, Samarasan expresses the following thoughts on the influences to her writing:

I think that the culture and history that most of us share ... manifest themselves in certain themes, a particular sense of humor, a particular relationship to language ... many of us grew up hearing a kind of old-fashioned, even bombastic, diction from our parents and grandparents, and I think this still colors our work. ("Guernica Fiction")

These words attest to the intricate relationship of language with the inherited and influential legacies of the persuasive power of the classics. This latter element is most strongly captured in the following scene that depicts Chellam, the domestic assistant of the Rajashekar household. Wrongfully accused of causing the death of the family matriarch Patti, Chellam is forced to leave the premises, and with it whatever little access she had to an income. The scene of her leavetaking is described through the point of view of Aasha Rajashekar, the youngest member of the family:

Aasha draws an elaborate picture indecipherable to everyone but herself, a picture of Chellam the ex-servant girl ... now in ex-ile in her faraway village of red earth and tin roofs. Ex-ile is an island for people who aren't what they used to be. On that lonely island in Aasha's picture Chellam wanders, tripping on blunt rocks in barren valleys, scaling sharp, windblown slopes on her hands and knees, minding starved cows that graze on rubbish heaps as if they're mounds of fresh clovers. (15) 
This vivid illustration accentuates the intertwining of both the local and the transnational imagination. In the image of the red earth, we have the signifier of the local Malaysian estate and the signature laterite pathways, as opposed to the tarred roads that exist in the mainly middleclass Rajashekar world. However, as the panorama of Chellam's departure unfolds, the scene converges into one that could very easily belong in the pages of the fiction of the Bronte sisters with the setting of the windswept, craggy hills and Catherine Earnshaw's eternal rocks of little visible light. As the transnational creative imaginary sutures the gaps in the memories of the ancestral landscape and threads through yarns of other imaginaries, the interspersing of the Bronte moors might however appear rather at odds with the familiar repertoire of geophysical descriptions of the land, especially to the Malaysian reader located within the physical nation space.

Then we have the depiction of the arrival of the pioneer member of the Rajashekar family in Penang in the nineteenth century:

In 1899, Appa's grandfather sailed across the Bay of Bengal to seek his fortune under familiar masters in a strange land, leaving behind an emerald of a village on the east coast of India. Barely had he shuffled off the boat with the rest of that vast herd in Penang when a fellow offered him a job on the docks, and here he toiled, sleeping four or five hours a night in a miserable dormitory, sending the bulk of his wages home, wanting nothing more for himself than to be able to pay his passage back home someday.

What changed his dreams in twenty years? All Appa's father, Tata, knew of it was that by the time he was old enough to stand before his father in knee-length khakis for morning inspections before school, his father was saying "Study hard. Study hard and you won't have to be a coolie like me." (17)

When seen from within the established context of diasporic memory, it reveals the collective unconscious of the diasporic literary archive (Mishra) in its rendition of the inherited memories of family history. The historical context is emphasized in the allusion to the precise year and the geographical setting. The homeland is also described in similar vein, with its regional emphasis. Color and physical cartography are foregrounded in the depiction of the arrival and consequent settling of the pioneer generation. The village that is left behind is summarily contained within a single metaphor, that of a gemstone. The narration emphasizes the sense of fatigue and drudgery of coolie life on the docks of Penang and the dismal living quarters that are received in exchange. A formal reading of the text reveals the expression of agency and assigns subject position to the immigrant: in 1899, Appa's grandfather sailed across the Bay of Bengal to seek his fortune, he 
shuffled off the boat, etc. The reference to the homeland as an emerald of a village also suggests that what he was leaving wasn't a difficult circumstance. Such use of ironically contrasting images suggests that the memory on which the text is written is very much both historical and romanticized, again a feature that is common in diasporic writings. Yet encapsulated within this depiction are also echoes of Other texts, of colonialist archival documentation of the arrival of coolies at the ports of Penang, such as the following passage from the "Report of the Commission of Enquiry into the State of Labour in the Straits Settlements and the Protected Native States" of the year 1890 :

On arrival in Penang, the ship is boarded by the Indian immigrant agent or his Assistant who inspects the coolies and sees that all the deck passengers ... are at once landed and sent to the depot ... The contract coolies are detained in the government depot until they sign the contracts and are handed over to the agents of the employers for transit to the estates where they are to work. (41)

The remembered mirror of memory thus glimmers with flecks of both folk and official narratives of the moment of the first migration. Added to this is also the fact that the notion of the retention of ancestral or folk memory does not follow the established pattern of most diasporic narratives. The homeland quickly recedes into the background, overshadowed by the grand narrative of migrant social mobility: "somewhere in all that hoping and studying and preparing, something else changed: India ceased to be home" (17) until eventually Appa's grandfather "had no pictures of his own to attach to his father's word for India" (18). The space of the ancestral homeland quickly becomes unrecognizable and detached, a centrifugal homeland.

Another significant image that stands out in the text is the family homestead, known as "The Big House" that the family patriarch purchases from a Scottish expatriate in Malaya:

Tata decided to buy himself a house that would declare his family's stake in the new country. A great house, a grand house, a dynastic seat....

In less than two years the house metamorphosed into something out of an Enid Blyton bedtime story. Unnecessary corridors met each other at oblique angles. Additions, partitions, and covered porches seemed to rise out of nowhere before the eye. Green mosquito netting thumbed its nose at the Battenburg lace curtains in the next room. Sweat and steam from the hot Indian kitchen invaded the immaculate English kitchen and smeared its shiny surfaces. And above it all the house's bold 
features - the quick, damning eyelids of the shutters, the sharp gable noses so different from the flat roofs around them - shuddered with a Scotman's thin lipped rancor. (1826)

There are two interesting aspects about the excerpt above. On the immediate and recognizable level, there is the hybridity of space, of the interlocking grids of transnational architectural features as western and eastern constructions mesh with each other. One might also read the almost disdainful appropriation of western space, as seen in the overpoweringly vibrant Asian hearth and the conflicting dialogics of the commonplace mosquito netting and the exquisite lace curtains. Then there is also the reference to Enid Blyton, yet another sign of an imagination colored by western canonical narratives, and with this the house is rendered into the realm of a child's imaginary world. However, as much as the narrative voice gravitates towards an almost sardonic visualization of the homestead, there are also strong indications of the diasporic individual's endeavor to carve a space within the environment of the new land. For as the narration continues, we learn that the exterior of the house is coated in a luminous blue: "Tata's last homeimprovement venture before he died was to paint the outside of the house an unapologetic peacock blue, as if to stamp upon the building his ownership, his nation's liberty and his own" (26). The exterior of the Big House becomes a space that exudes a sense of nostalgia for the homeland; the color blue, aptly called "mughal blue" and "peacock blue" (26), are symbols of a majestic India. The actions of Appa, who methodically selects the same color every year when repainting the house, is also an indication of the diasporic imagination's grasp of tradition and familiarity with the homeland. These signify an almost subliminal desire to continuously engage with the homeland even whilst painting a new space of home, as they literally create and coat a new space of home, recast in splendid color, as if to call colorful witness to their presence. This can be read as an apt metaphor for the creative imaginary of the writer as a palette of different memories, colored both by oral and narrative history. However, the cracks and fissures are still evident beneath these layers of coatings.

What we see then are the gossamer threads of what appears to be a distanced and disappearing motherland, which brings me to the final point of the paper, the various allusions to alienating mother-daughter relationships which can be translated as metaphors of an estranged motherland, Malaysia. The majority of scholarship on diasporic women's writings, specifically Asian women's writing, emphasizes the aspect of maternal bonding, of writing for their mothers. Amy Tan, for instance, has expressed in interview: 
When I was writing, it was so much for my mother and myself.... I wanted her to know what I thought about China and what I thought about growing up in this country. And I wanted those words to almost fall off the page so that she could just see the story, that the language would be simple enough, almost like a little curtain that would fall away. (qtd. in Heung 598)

It emphasizes the bond between mother and daughter and the lifting of the shrouds of intergenerational communication. However, in Samarasan's novel, the mother-daughter (and, we might add, grandmother-grandaughter) relationship appears to be one that is heavily curtained by severe dysfunction and a haunting silence. Foremost is the relationship between the older Mrs. Rajashekar or Paatti, the younger Mrs. Rajashekar or Amma, and Aasha and Uma, the younger generation of Rajashekar women. The flow of memory between each generation seems to be embodied within ethereal figurations caught in the realm of the beyond. Take the following excerpt:

There'1l be new ghosts in the house: the ghost of dead Paati, growing younger and older and younger again, wrinkles melting into dimples and dimples into hollows, now a toddler, now a bride, now an old lady with a back as curved as a coconut shell; the ghost of Uma Past, suspended in time and forever eighteen years old. (9)

And also the one below:

When Aasha trails the new Uma around the house, the old one walks behind them both, soft-footed, humming under her breath. (29)

The ghosts that drift across the narrative space are such complex figures caught in transit between the here and the hereafter, included in the narrating vision yet ephemeral in nature. Witness the Dickensian allusion here, too, of ghosts of the past and of the present. Furthermore, the fact that all the ghosts that appear in the novel are female can be read as a subliminal metaphor for the estranged motherland, Malaysia, seen within the context of a hauntingly restless relationship of maternal disengagement.

Even when mother-daughter encounters are located outside the ghostly realm, they reveal similar disjunctures of communication. We are presented with Amma's view of Aasha as a "child grabbing at her life with its sticky fingers, a child that had crawled out of her only six years ago, 
transformed in eight difficult hours from an internal parasite to an external one" (186). We are also told of pictures of "Uma and Amma standing exactly a foot apart," and when Uma leaves for the US, the recollection is that "Amma grabs the stiff scarecrowness of Uma by the shoulders and gives it an arm's-length hug" (333). While at one level, these images point to the disjunctured maternal relationship and will certainly engender multiple readings against a feminist praxis, within the transnational context of this paper and of the creative imaginary of the novelist, these might also be viewed against the pattern of the various images of estrangement noted from the outset of the discussion of this section.

Language is also another indicator of the breakdown and dysfunctional relationship that tether both mother and daughter. In a particular scene at the train station, Amma and a young Uma are waiting for the arrival of the train to take them to Amma's sister Valli's home. It is important to also note that the train station is one among the few spaces that characters from other religious and ethnic diversity seep into the narrative and encounter the main characters. It is also a space that indicates the racial tension and clashes that churn at the bustling surface of the busy train station. It is both foreign culture and people that Uma encounters for the first time since leaving her secluded and predominantly Eurocentric life in the Big House. At the train station, Uma, baffled by the alienating space, ask her mother what the meaning of a specific word in Malay meant, “'What does it mean, Amma?' Uma asked. 'Carry-tuppy Tanah Me-lay-oo?' Her mother however is unable to translate the word and briskly replies, 'Uma, don't start ... You know I don't know all that. I didn't study their wonderful Malay language in school'"' (115). This interaction that is abruptly halted hinders the transference of knowledge about the national language. It elucidates the fragmented and estranged relationship between mother and daughter. Amma's inablity to comprehend the Malay language indicates the disturbance of the flow of knowledge, stunting the maternal relationship. The space of the motherland or homeland then emerges as alienating and impenetrable because of the lack of knowledge to comprehend it, further disrupting the matrilineal relationship within the narrative. The estranged mother-daughter relationship epitomizes an almost disoriented transnational creative vision that, when viewed against the representation of Malaysia, reveals resonances of matrilineal estrangement from the motherland, the visualization of the disembodied birdlike peninsular, the palimpsest of the Malaysian geographical landscape reinscribed as moorlands, and the equally strange monotony of its climate.

\section{CONCLUSION}

Throughout it all, as much as the novel reflects the various transformative shifts that memory and material culture undergo through transnational voyages, the multiple passages 
through immeasurable borders and portals, the writer is at once both insider and outsider, including yet excluding, with every ordained arrival and departure of migration, emigration or trans-movement. As the fragments of the mirror of the nation are pieced together in Samarasan's novel, Other segments make their way into the gaps in the mainframe and are fastened by the adhesive of creative expression. These can be seen as signifiers of transnational memory, looking across time and space, intersecting with the inherited memory of Malaysia. These, too, then are the factors that ought to be kept in mind when such writings are hailed as authentic representations of contemporary nation states. For as Chow has cautioned, one needs to be cognizant of the fact that these are caught within "the problematic of the post-colonial discursive space in which many 'third-world' intellectuals who choose to live in the 'first world' function ... serving as providers of knowledge about their nations and cultures ... cultural workers/brokers in diaspora" (93). The creative writer occupies a similar space, for as in Graham Huggan's words, "What is at stake here, in other words, is not just the cultural authenticity-or lack of it-supposedly embodied in these writers and their writings, but the degree of agency they are able to exercise over the production and, no less important, the subsequent reception of their book" (138).

As we turn the last page and reminisce over the ethnic representation, we need also to remember that these are but imaginary homelands, refracted from the shards of a broken mirror, recast within a synchronic transnational warehouse of memories. Be this as it may, these can stand also as testimony of the ever increasing heterogeneity of the transnational creative imaginary that leads then not to one distinct imaginary of Malaysia from afar but rather the imaginaries that arise of the ties that do not bind when one stands across a bridge of transnational boards and boarding passes, more than a foot apart from an estranged motherland. 


\section{WORKS CITED}

Appadurai, Arjun. "Disjuncture and Difference in the Global Cultural Economy." Theorizing Diaspora: A Reader. Eds. Jana Evans Braziel and Anita Mannur. Oxford: Blackwell, 2003. 25-48. Print.

Ang, Ien. "Migrations of Chineseness." SPAN: Journal of the South Pacific Association for Commonwealth Literature and Language Studies 34-35 (1993): 1-9. Print.

Chow, Rey. Writing Diaspora: Tactics of Intervention in Contemporary Cultural Studies. Bloomington and Indianapolis: Indiana UP, 1993. Print.

Cohen, Robin. Global Diaspora: An Introduction. London: UCL Press, 1997. Print.

Ee Tiang Hong. Tranquerah. Singapore: Dept. of English Language and Literature, National U of Singapore, 1985. Print.

Gilroy, Paul. "Diaspora." Migration, Diasporas, and Transnationalism. Eds. Steven Vertovec and Robin Cohen. Northampton, Mass.: Edward Elgar, 1999. 293-98. Print.

“Guernica Fiction Continued with P. Samarasan.” Sepia Mutiny. 21 Nov. 2009. Web. 21 Jan. 2011.

Heung, Marina."Daughter-Text/Mother-Text: Matrilineage in Amy Tan's Joy Luck Club." Feminist Studies, Inc.19.3 (1993): 596 - 616. Print.

Huggan, Graham. The Postcolonial Exotic: Marketing the Margins. London: Routledge, 2001. Print.

Lim, Shirley Geok-Lin. Among the White Moon Faces: Memoirs of a Nyonya Feminist. Singapore: Times Books International, 1996. Print.

Mishra, Vijay. The Literature of the Indian Diaspora: Theorising the Diasporic Imaginary. London: Routledge, 2007. Print.

Pillai, Shanthini. Colonial Visions, Postcolonial Re-visions: Images of the Indian Diaspora in Malaysia. Newcastle Upon Tyne: Cambridge Scholars, 2007. Print.

"Preeta Samarasan 2010 PEN/O. Henry Award-Winning Author." Random House. 2010. Web. 9 Jan. 2012.

Quayum, Mohammad A., and Shirley Lim Geok-lin. "Shirley Geok-lin Lim: An Interview." Melus, Speech and Silence: Ethnic Women Writers 28.4 (2003): 83-100. Mendeley. Web. 30 Jan. 2012.

Rushdie, Salman. Imaginary Homelands. London: Penguin, 1991. Print.

Samarasan, Preeta. Evening is the Whole Day. London: Fourth Estate, 2008. Print.

Straits Settlements. Report of the Commission of Enquiry into the State of Labour in the Straits Settlements and the Protected Native States, 1890.

Subramaniam, Ganakumaran, and Shanthini Pillai. "Reconciling Malaysian Chinese Identity: Multiple Passages to Nationhood." SARE: Southeast Asian Review of English 48 (2009): 56-74. Print. 